\title{
Rolling Bearing Fault Detection Based on the Teager Energy Operator and Elman Neural Network
}

\author{
Hongmei Liu, ${ }^{1}$ Jing Wang, ${ }^{1}$ and Chen Lu, ${ }^{1,2}$ \\ ${ }^{1}$ School of Reliability and Systems Engineering, Beihang University, No. 37, Xueyuan Road, Haidian District, Beijing 100191, China \\ ${ }^{2}$ Science \& Technology Laboratory on Reliability \& Environmental Engineering, Beijing 100191, China \\ Correspondence should be addressed to Chen Lu; luchen@buaa.edu.cn
}

Received 7 February 2013; Revised 26 April 2013; Accepted 28 April 2013

Academic Editor: Ping-Lang Yen

Copyright (c) 2013 Hongmei Liu et al. This is an open access article distributed under the Creative Commons Attribution License, which permits unrestricted use, distribution, and reproduction in any medium, provided the original work is properly cited.

\begin{abstract}
This paper presents an approach to bearing fault diagnosis based on the Teager energy operator (TEO) and Elman neural network. The TEO can estimate the total mechanical energy required to generate signals, thereby resulting in good time resolution and self-adaptability to transient signals. These attributes reflect the advantage of detecting signal impact characteristics. To detect the impact characteristics of the vibration signals of bearing faults, we used the TEO to extract the cyclical impact caused by bearing failure and applied the wavelet packet to reduce the noise of the Teager energy signal. This approach also enabled the extraction of bearing fault feature frequencies, which were identified using the fast Fourier transform of Teager energy. The feature frequencies of the inner and outer faults, as well as the ratio of resonance frequency band energy to total energy in the Teager spectrum, were extracted as feature vectors. In order to avoid a frequency leak error, the weighted Teager spectrum around the fault frequency was extracted as feature vector. These vectors were then used to train the Elman neural network and improve the robustness of the diagnostic algorithm. Experimental results indicate that the proposed approach effectively detects bearing faults under variable conditions.
\end{abstract}

\section{Introduction}

Bearing failure is one of the main causes of breakdown in rotating machinery, often resulting in worker injury or equipment damage, mission-critical failure, and costly system downtime. For these reasons, the detection of bearing faults has been the subject of extensive research. Vibration signals are usually collected to diagnose bearing faults. In practical industrial fields, however, the vibration signals of bearings are typically complex because of the effects of the working environment; detecting bearing faults only by observing the fast Fourier transform (FFT) of bearing measurement signals is difficult. Researchers have proposed numerous techniques for analyzing the frequency domain of vibration signals. FFT is generally used to generate vibration signal spectra, and the application of reasonable window functions and smoothing techniques can improve the quality of the frequency analysis of vibration signals $[1,2]$. The primary purposes of such analyses are to identify the feature frequencies of bearing faults and use the parameters related to feature frequencies to diagnose bearing faults. To solve the interference of weak bearing fault signals during the extraction of vibration signal features from strong broadband noise, scholars proposed envelopment analysis; this method is extensively used, particularly for early fault detection [3-5]. Envelopment analysis can extract periodic pulses or amplitude-modulated signals from vibration signals. At increasingly severe bearing damage, however, bearing vibration mode becomes irregular and exhibits more random features. This irregularity makes envelopment analysis invalid for identifying feature frequency. Logarithmic cepstrum analysis was originally proposed for processing seismic data in an echo problem and was then gradually extended to the analysis of bearing vibration signals. Similar to envelopment analysis, the function of the logarithmic cepstrum in vibration signal analysis is to detect the harmonics and subband corresponding to the feature frequencies of bearing faults [6]. The difference is that envelopment analysis is applied to a particular band of a vibration signal, whereas the logarithmic cepstrum is used to analyze the vibration 
signals in the entire frequency domain. Nonetheless, the logarithmic cepstrum is rarely used in bearing fault detection possibly because such analysis requires the use of a computer and involves relatively complex interpretation of results. A wavelet transform is used in time-frequency analysis that has the characteristics of multiresolution analysis. Given that its time-frequency localization characteristics more accurately represent nonstationary signals, wavelet transforms have been frequently applied to bearing fault detection in the last 20 years [7]. A discrete wavelet transform is based on two subfrequency splits, which causes man-made damage to the feature frequency bands of bearing faults; in practical bearing fault detection, a continuous wavelet transform is typically used to analyze vibration signals. To a certain extent, this limits the application of wavelet transforms in systems that demand high computing speed and large storage capacity. Furthermore, similar to envelopment analysis, identifying the feature frequency of the bearing fault of a vibration spectrum becomes impossible at severe bearing damage.

The Teager energy operator (TEO) has recently been applied in processing nonlinear signals. It is a type of nonlinear differential operator that estimates the total energy (kinetic energy and potential energy) produced by a signal source through the instantaneous value of a signal and a differential nonlinear combination. Therefore, the TEO can enhance the transient features of a signal, making it suitable for detecting impact signals. The TEO has a high time resolution and a good adaptability to the instantaneous changes in signals. Kaiser put forward and improved the TEO, as well as processed voice signals by applying this criterion [8]. Hongxing et al. verified the validity of the TEO by using a compressor vibration signal, comparing the performance of TEO demodulation with that of Hilbert envelope transform demodulation [9]. Bassiuny and Li used empirical mode decomposition to separate the amplitude modulation signal and frequency modulation signal of a machine tool feed motor and then applied the TEO demodulation method to calculate the instantaneous amplitude and instantaneous frequency of intrinsic mode functions; time-frequency information was constructed to monitor the condition of the machine tool [10]. To extract the cyclical shock feature of a bearing fault, this paper presents a TEObased method for extracting the features of bearing vibration signals. The TEO showed the advantages of detecting the transient components of a signal, an approach that enhances the impact characteristics of the vibration signals of bearing faults. The faults are detected through feature frequencies obtained from the FFT of Teager energy.

As depicted in Figure 1, considering the advantage of the TEO in detecting transient impact, this study presents a bearing fault detection method based on this criterion. First, the TEO output of the original vibration signal of the bearing fault was calculated to analyze the cyclical characteristic of the transient impact. The instantaneous Teager energy sequence was denoised by wavelet packet and Fourier transformed to obtain the Teager spectrum. The fault feature frequencies differ under various faults, and for various types of bearing faults, the energies in the resonance frequency band also differ. The amplitude of the Teager spectrum around the fault
TABLE 1: Feature vectors.

\begin{tabular}{cccc}
\hline & Inner ring & Outer ring & Ratio of energy \\
\hline Feature vector & $F_{\text {in }} \pm \Delta f$ & $F_{\text {out }} \pm \Delta f$ & $E_{1} / E_{0}$ \\
\hline
\end{tabular}

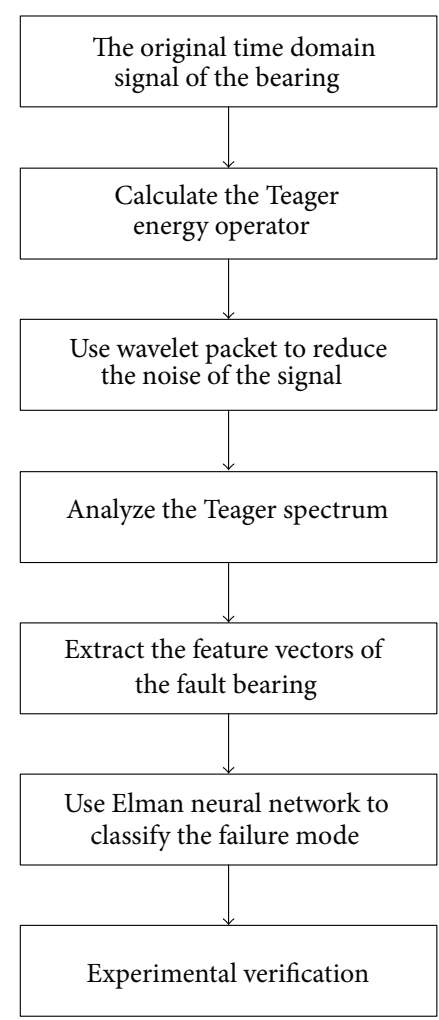

FIgURE 1: The flow chart of the proposed method.

frequencies of the inner and outer rings (within $\pm \Delta f \mathrm{~Hz}$ ) and the ratio of resonance band energy to total energy were extracted as the feature vectors used to train the Elman neural network.

In Table $1, F_{\text {in }}$ represents the feature frequency of the inner ring, $F_{\text {out }}$ denotes the feature frequency of the outer ring, $E_{1}$ is the sum of Teager energy from $2000 \mathrm{~Hz}$ to 4000 $\mathrm{Hz}$, and $E_{0}$ represents the sum of total Teager energy.

This paper is organized as follows. Section 2 introduces the principle of TEO-based feature extraction. The Teager energy signal denoising by wavelet packet and fault classification by the Elman neural network are presented in Sections 3 and 4, respectively. The experimental results are reported in Section 5. Conclusions are drawn in the final section.

\section{Principle of TEO-Based Feature Extraction}

For any signal $x(t)$, TEO $\psi$ is defined as [11]

$$
\psi[x(t)]=[\dot{x}(t)]^{2}-x(t) \ddot{x}(t),
$$

where $\dot{x}(t)$ and $\ddot{x}(t)$ represent the first- and second-order time differential of $x(t)$. The output of the TEO monitors the total energy required to produce a signal. In a linear undamped vibration system that consists of a mass and 


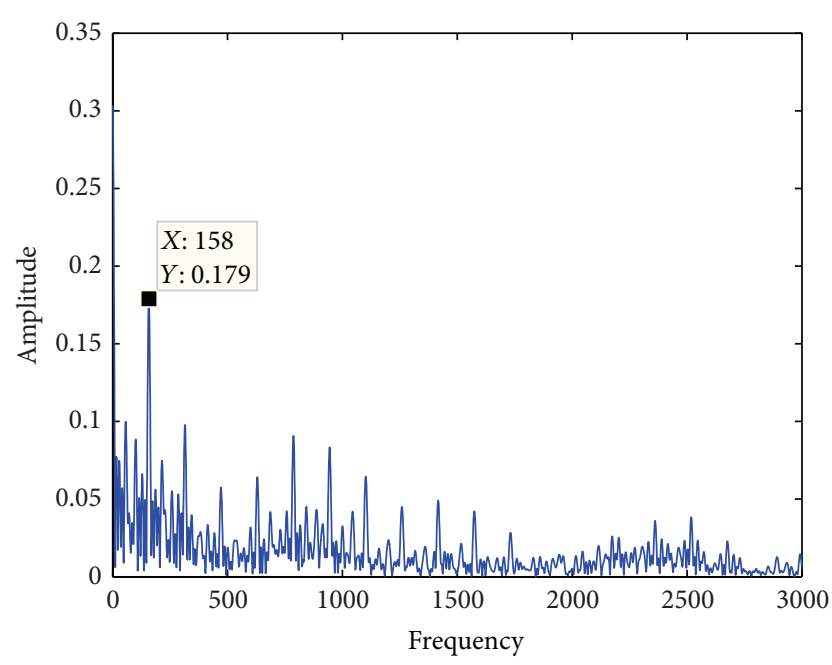

FIGURE 2: Teager energy spectrum of the ordinary inner ring fault bearing.

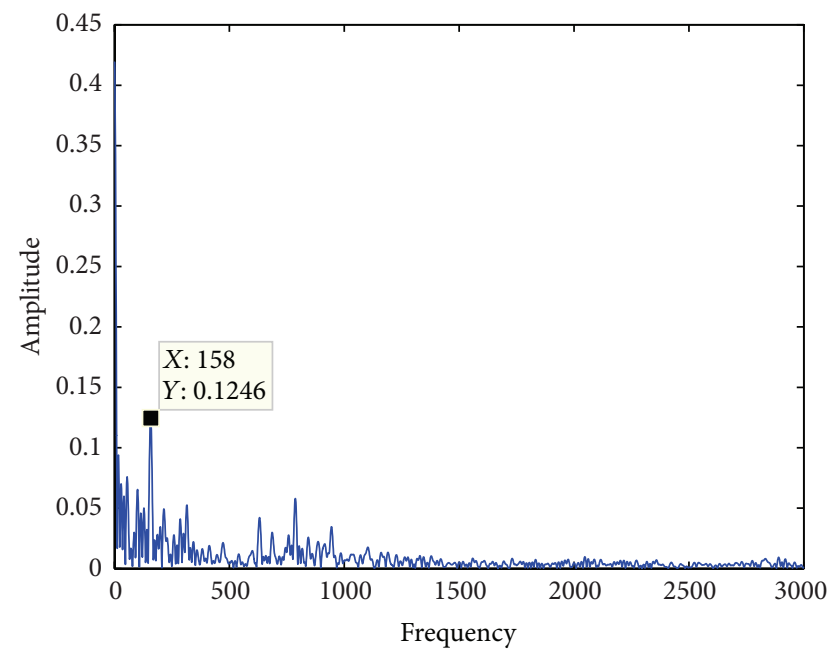

FIGURE 3: Hilbert-Huang spectrum of the ordinary inner ring fault bearing.

a spring, the second-order differential equation according to Newton's laws of motion is

$$
m \ddot{x}(t)+k x(t)=0,
$$

where $x(t)$ represents the mass displacement relative to the equilibrium position, $\ddot{x}(t)$ denotes the acceleration, $k$ represents a stiffness coefficient of the spring, and $m$ is the weight of the mass. This equation describes the movement of the mass, and its solution is a simple harmonic motion:

$$
x(t)=A \cos (\omega t+\varphi) .
$$

Correspondingly, its velocity and acceleration are

$$
\begin{aligned}
\dot{x}(t) & =-A \omega \sin (\omega t+\varphi), \\
\ddot{x}(t) & =-A \omega^{2} \cos (\omega t+\varphi),
\end{aligned}
$$

TABLE 2: Bearing specifications.

(a) Size: (in)

\begin{tabular}{lcccc}
\hline $\begin{array}{l}\text { Inner } \\
\text { diameter }\end{array}$ & $\begin{array}{c}\text { Outer } \\
\text { diameter }\end{array}$ & Thickness & $\begin{array}{c}\text { Ball } \\
\text { diameter }\end{array}$ & $\begin{array}{c}\text { Pitch } \\
\text { diameter }\end{array}$ \\
\hline 0.9843 & 2.0472 & 0.5906 & 0.3126 & 1.537 \\
\hline
\end{tabular}

(b) Defect frequencies: (multiples of running speed in $\mathrm{Hz}$ )

\begin{tabular}{lccc}
\hline Inner ring & Outer ring & Cage train & $\begin{array}{c}\text { Rolling } \\
\text { element }\end{array}$ \\
\hline 5.4152 & 3.5848 & 0.39828 & 4.7135 \\
\hline \multicolumn{4}{c}{ TABLE 3: Feature vectors. } \\
\hline & Inner ring $(\mathrm{Hz})$ & Outer ring $(\mathrm{Hz})$ & Ratio of energy \\
\hline Feature vector & $E\left(F_{\text {in }} \pm 2\right)$ & $E\left(F_{\text {out }} \pm 2\right)$ & $E_{1} / E_{0}$ \\
\hline
\end{tabular}

TABle 4: Training data.

\begin{tabular}{lcccc}
\hline $\begin{array}{l}\text { Signal type } \\
(1750 \mathrm{rpm})\end{array}$ & Target output & \multicolumn{3}{l}{ Input of the Elman neural network } \\
\hline \multirow{4}{*}{ Normal } & $(1,0,0)$ & 0.0005 & 0.0005 & 0.1769 \\
& $(1,0,0)$ & 0.0006 & 0.0005 & 0.1760 \\
& $(1,0,0)$ & 0.0007 & 0.0005 & 0.1757 \\
& $(1,0,0)$ & 0.0007 & 0.0005 & 0.1765 \\
& $(1,0,0)$ & 0.0007 & 0.0006 & 0.1760 \\
\hline \multirow{3}{*}{ fnner ring } & $(0,1,0)$ & 0.3274 & 0.8753 & 0.1548 \\
& $(0,1,0)$ & 0.3269 & 0.8751 & 0.1548 \\
& $(0,1,0)$ & 0.3267 & 0.8749 & 0.1548 \\
& $(0,1,0)$ & 0.3269 & 0.8750 & 0.1548 \\
fult & $(0,1,0)$ & 0.3192 & 0.8833 & 0.1551 \\
\hline \multirow{4}{*}{ fault } & $(0,0,1)$ & 4.6878 & 0.8272 & 0.0577 \\
& $(0,0,1)$ & 4.6851 & 0.8230 & 0.0576 \\
& $(0,0,1)$ & 4.6846 & 0.8216 & 0.0576 \\
& $(0,0,1)$ & 4.6821 & 0.8199 & 0.0576 \\
& $(0,0,1)$ & 4.6840 & 0.8188 & 0.0576 \\
\hline
\end{tabular}

where $A$ represents the amplitude of vibration and $\varphi$ represents the initial phase, and $(\mathrm{k} / \mathrm{m})^{1 / 2}$ represents the natural frequency.

At any time, the mechanical energy of the vibration system is the sum of the potential energy of the spring and the kinetic energy of the mass:

$$
E=\frac{1}{2} k[x(t)]^{2}+\frac{1}{2} m[\dot{x}(t)]^{2} .
$$

Substituting (3) and (4) into (6) yields the total energy thus

$$
E=\frac{1}{2} m A^{2} \omega^{2}
$$

Equation (7) shows the instantaneous total energy of the harmonic vibration, and the square of the amplitude is inversely proportional to the square of the frequency. 
TABLE 5: Test results.

\begin{tabular}{|c|c|c|}
\hline $\begin{array}{l}\text { Signal type } \\
(1750 \mathrm{rpm})\end{array}$ & Expected output & Actual output \\
\hline \multirow{5}{*}{ Normal } & \multirow{5}{*}{$(1,0,0)$} & $\begin{array}{lll}1.0023 & 0.0012 & 0.0008\end{array}$ \\
\hline & & $\begin{array}{llll}\mathbf{0 . 9 9 8 7} & 0.0008 & 0.0006\end{array}$ \\
\hline & & $\begin{array}{lll}0.9993 & 0.0005 & -0.0001\end{array}$ \\
\hline & & $\begin{array}{lll}\mathbf{0 . 9 9 7 4} & 0.0007 & 0.0004\end{array}$ \\
\hline & & $\begin{array}{llll}\mathbf{0 . 9 9 8 8 6} & 0.0009 & 0.0006\end{array}$ \\
\hline \multirow{5}{*}{ Inner ring fault } & \multirow{5}{*}{$(0,1,0)$} & $\begin{array}{lll}0.0023 & 1.0013 & 0.0012\end{array}$ \\
\hline & & $\begin{array}{lll}0.0017 & 1.0001 & -0.0017\end{array}$ \\
\hline & & $\begin{array}{lll}0.0021 & \mathbf{0 . 9 9 9 2} & 0.0008\end{array}$ \\
\hline & & $\begin{array}{lll}0.0011 & 0.9995 & 0.0015\end{array}$ \\
\hline & & $\begin{array}{lll}0.0013 & 1.0012 & 0.0004\end{array}$ \\
\hline \multirow{5}{*}{ Outer ring fault } & \multirow{5}{*}{$(0,0,1)$} & $\begin{array}{lll}-0.0021 & -0.0012 & 1.0009\end{array}$ \\
\hline & & $\begin{array}{lll}-0.0015 & -0.0002 & 1.0017\end{array}$ \\
\hline & & $\begin{array}{lll}0.0032 & 0.0027 & \mathbf{0 . 9 9 5 6}\end{array}$ \\
\hline & & $\begin{array}{lll}-0.0034 & -0.0018 & 1.0032\end{array}$ \\
\hline & & $\begin{array}{lll}0.0085 & 0.0036 & \mathbf{0 . 9 8 7 8} \\
\end{array}$ \\
\hline $\begin{array}{l}\text { Signal type } \\
(1772 \mathrm{rpm})\end{array}$ & Expected output & Actual output \\
\hline \multirow{5}{*}{ Normal } & \multirow{5}{*}{$(1,0,0)$} & $\mathbf{0 . 9 9 8 9}-0.0054 \quad-0.0214$ \\
\hline & & $\mathbf{0 . 9 9 8 7}-0.0058-0.0243$ \\
\hline & & $\begin{array}{lll}1.0002 & -0.0073 & -0.0317\end{array}$ \\
\hline & & $\begin{array}{llll}0.9973 & -0.0066 & -0.0293\end{array}$ \\
\hline & & $\begin{array}{llll}\mathbf{0 . 9 9 9 7} & -0.0068 & -0.0312 \\
\end{array}$ \\
\hline \multirow{5}{*}{ Inner ring fault } & \multirow{5}{*}{$(0,1,0)$} & $\begin{array}{lll}0.2521 & 0.9967 & -0.0009\end{array}$ \\
\hline & & $\begin{array}{llll}0.2546 & 0.9949 & -0.0031\end{array}$ \\
\hline & & $\begin{array}{lll}0.2524 & 0.9989 & -0.0015\end{array}$ \\
\hline & & $\begin{array}{lll}0.2521 & \mathbf{0 . 9 9 9 5} & -0.0014\end{array}$ \\
\hline & & $\begin{array}{llll}0.2523 & 1.0012 & -0.0014 \\
\end{array}$ \\
\hline \multirow{5}{*}{ Outer ring fault } & \multirow{5}{*}{$(0,0,1)$} & $\begin{array}{lll}0.0769 & -0.1424 & \mathbf{1 . 0 0 0 2}\end{array}$ \\
\hline & & $\begin{array}{lll}0.0774 & -0.1429 & \mathbf{0 . 9 9 9 2}\end{array}$ \\
\hline & & $\begin{array}{lll}0.0777 & -0.1430 & \mathbf{0 . 9 9 6 7}\end{array}$ \\
\hline & & $\begin{array}{lll}0.0779 & -0.1438 & 1.0001\end{array}$ \\
\hline & & $\begin{array}{lll}0.0781 & -0.1444 & \mathbf{0 . 9 9 7 6}\end{array}$ \\
\hline $\begin{array}{l}\text { Signal type } \\
(1721 \mathrm{rpm})\end{array}$ & Expected output & Actual output \\
\hline \multirow{5}{*}{ Normal } & \multirow{5}{*}{$(1,0,0)$} & $\begin{array}{lll}0.9989 & -0.1411 & 0.2092\end{array}$ \\
\hline & & $\mathbf{0 . 9 9 6 2}-0.1401 \quad 0.2066$ \\
\hline & & $\mathbf{0 . 9 9 6 1} \quad-0.1330 \quad 0.1877$ \\
\hline & & $\mathbf{0 . 9 9 6 1}-0.1334 \quad 0.1886$ \\
\hline & & $\begin{array}{lll}\mathbf{0 . 9 9 6 1} & -0.1347 & 0.1913 \\
\end{array}$ \\
\hline \multirow{5}{*}{ Inner ring fault } & \multirow{5}{*}{$(0,1,0)$} & $\begin{array}{lll}0.0082 & \mathbf{0 . 9 9 4 3} & 0.1207\end{array}$ \\
\hline & & $\begin{array}{lll}0.0050 & \mathbf{0 . 9 9 4 9} & 0.1206\end{array}$ \\
\hline & & $\begin{array}{lll}0.0054 & \mathbf{0 . 9 9 3 9} & 0.1199\end{array}$ \\
\hline & & $\begin{array}{lll}0.0035 & \mathbf{0 . 9 9 4 4} & 0.1200\end{array}$ \\
\hline & & $\begin{array}{lll}-0.0001 & \mathbf{0 . 9 9 5 1} & 0.1230\end{array}$ \\
\hline
\end{tabular}

TABle 5: Continued.

\begin{tabular}{lllll}
\hline & & 0.0608 & 0.0854 & $\mathbf{0 . 9 9 6 3}$ \\
Outer ring fault & $(0,0,1)$ & 0.0609 & 0.0855 & $\mathbf{0 . 9 9 6 1}$ \\
& & 0.0614 & 0.0859 & $\mathbf{0 . 9 9 6 7}$ \\
& 0.0617 & 0.0871 & $\mathbf{0 . 9 9 7 2}$ \\
& 0.0615 & 0.0862 & $\mathbf{0 . 9 9 7 0}$ \\
\hline
\end{tabular}

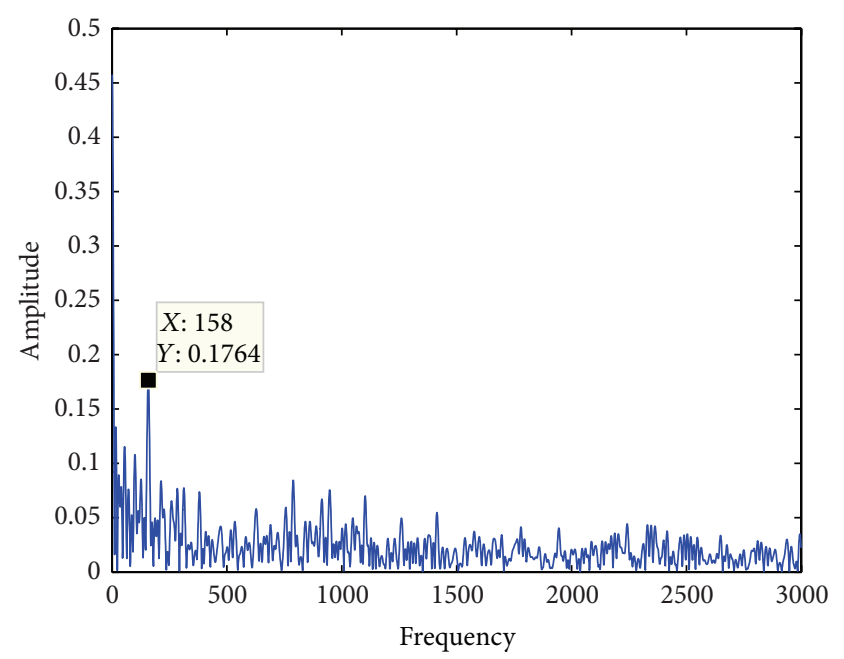

FIgURE 4: Teager energy spectrum of the inner ring fault bearing working in the harsh condition.

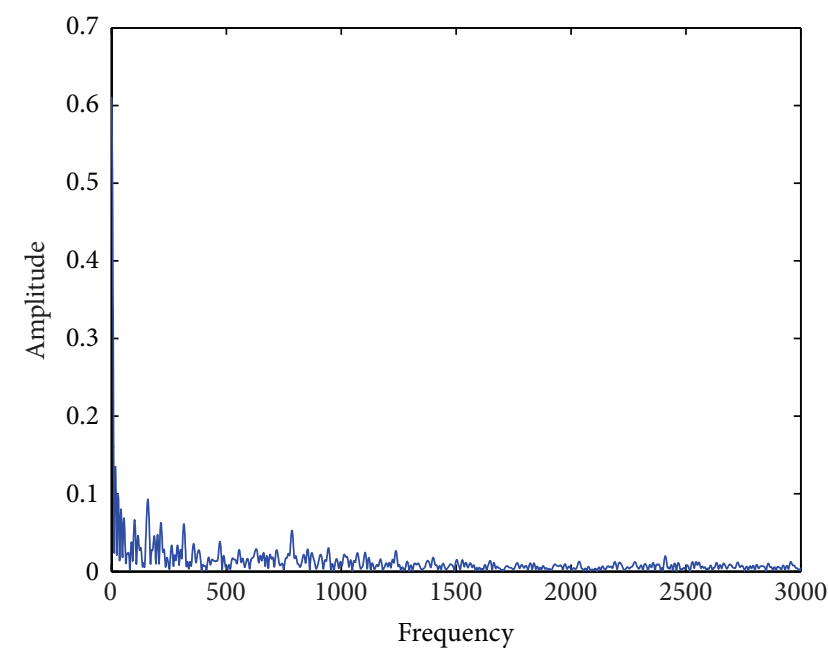

FIGURE 5: Hilbert-Huang spectrum of the inner ring fault bearing working in the harsh condition.

From the aforementioned equations, we can obtain that

$$
\psi[x(t)]=\psi[A \cos (\omega t+\varphi)]=A^{2} \omega^{2} .
$$

Comparing (7) and (8), the only difference is the constant $\mathrm{m} / 2$ between the output of the TEO and the instantaneous total energy of the simple harmonic motion. 


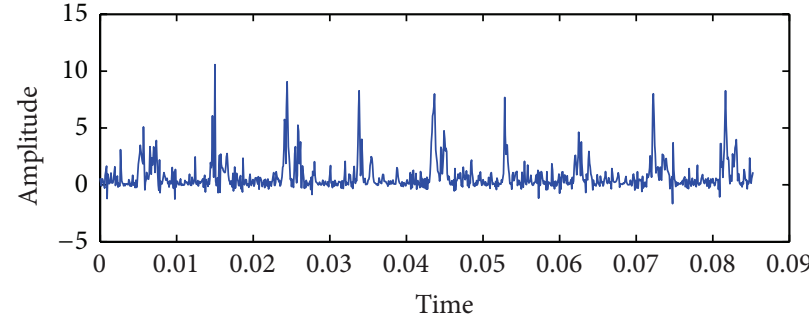

(a)

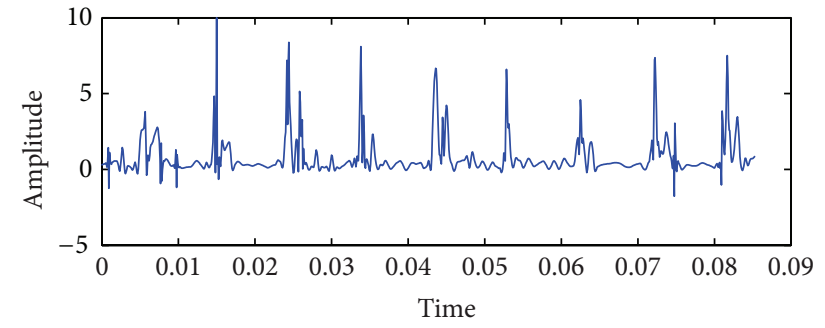

(b)

Figure 6: Time domain waveform of Teager energy without and with wavelet packet-based denoising.

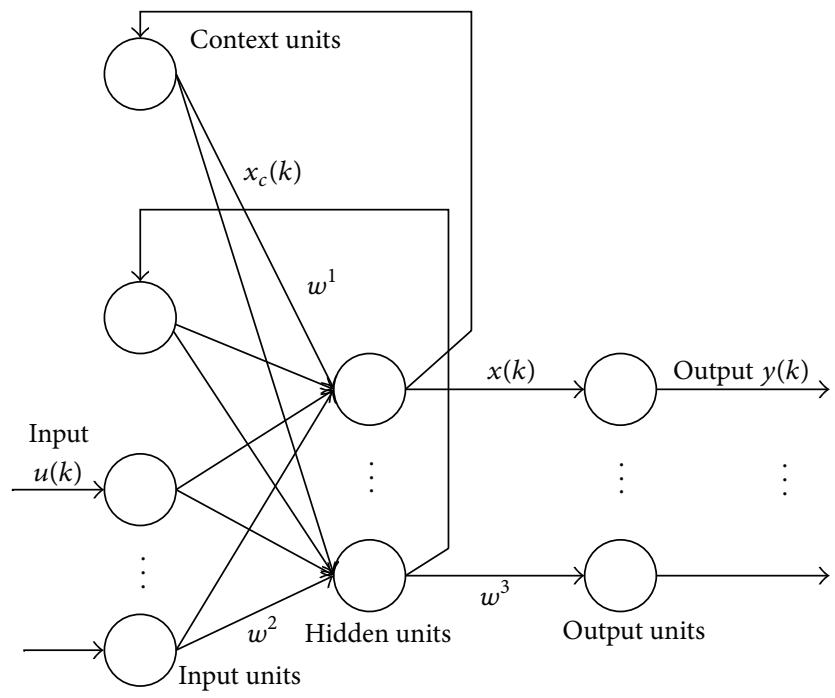

FIGURE 7: Elman neural network.

For discrete-time signal $x(t)$, the difference equation is used instead of the differential equation:

$$
\psi[x(n)]=[x(n)]^{2}-x(n-1) x(n+1) .
$$

For the discrete-time signal, the TEO needs only three samples to calculate the energy of the signal at any time. Therefore, the TEO has a good time resolution for the instantaneous change in the signal and can detect the transient components of the signal.

If the inner rings, outer rings, or rolling elements of rolling bearings have abrasions, cracks, pointed corrosions, or other local damages, the impact phenomenon caused by the mutations in vibration energy will occur when the damage point goes through the other components. This impact will intensify the resonance of the bearing components, and the resonance will rapidly increase. Therefore, the transient shock vibration caused by the bearing fault not only dramatically changes the amplitude of the vibration signal but also generates a higher frequency. Traditional signal energy is defined as the square of the signal amplitude, and it can represent only kinetic or potential energy. Although this method can highlight transient impact features, impact signals may be masked by other components if the impact is

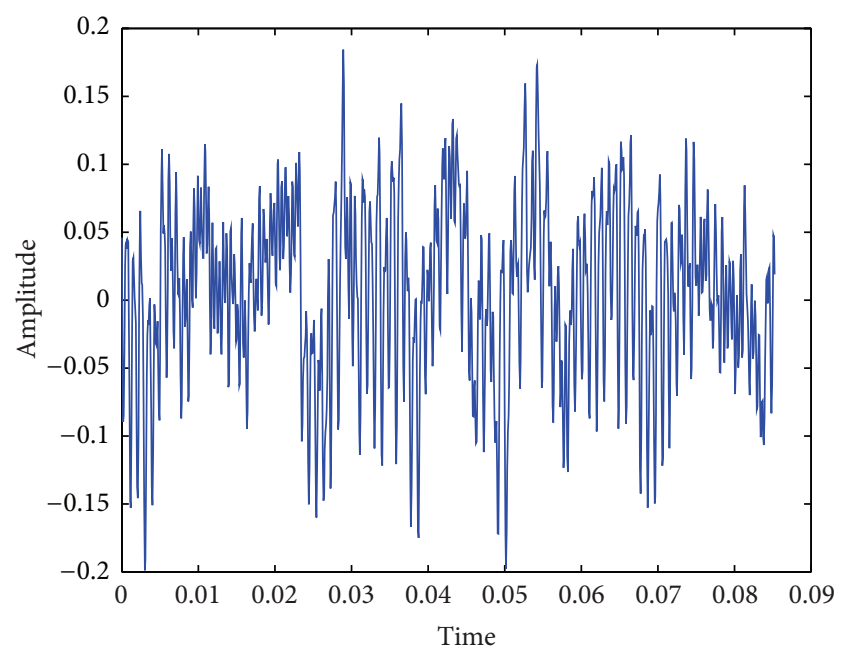

Figure 8: Time domain waveform of the vibration signal at normal conditions.

of small amplitude. The TEO can monitor the total energy of signals, including kinetic and potential energy, whose output is the square of the product of the instantaneous amplitude and the instantaneous frequency of the vibration. Compared with traditional signal energy, the TEO considers the frequency of a signal. Given the high frequency of transient impact vibration, the TEO can more effectively highlight the transient characteristics of the impact.

In order to show the advantage of the TEO method, the Hilbert-Huang was used to compare.

These two figures in Figures 2 and 3 show the Teager and Hilbert spectrums can both extract the feature frequency from the rolling bearing signal when the bearing have the ordinary inner ring fault.

However, if the rolling bearing works in harsh conditions, the TEO will show its advantage. To demonstrate it, the white noise with an SNR of 0.6 is introduced into the original vibration signal.

As shown in Figures 4 and 5, the TEO can successfully identify the feature frequency when the rolling bearing works in harsh conditions, whereas the Hilbert-Huang exhibits low performance in this regard. 


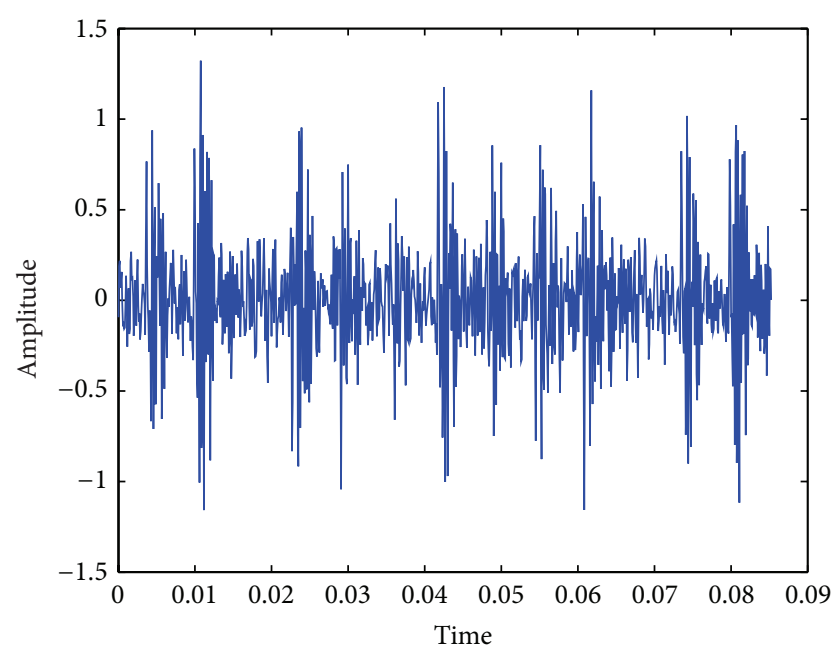

FIGURE 9: Time domain waveform of the vibration signal at inner ring fault conditions.

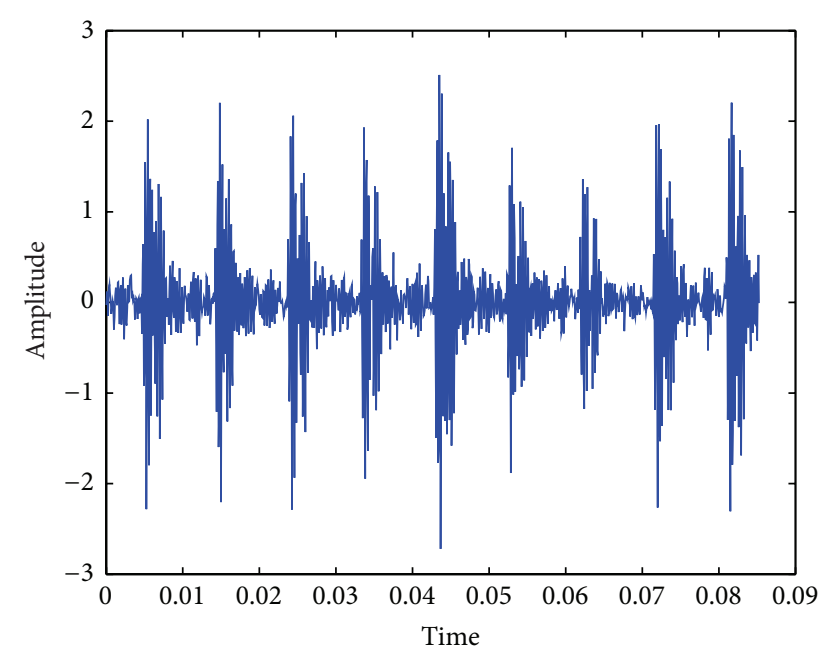

FIGURE 10: Time domain waveform of the vibration signal at outer ring fault conditions.

\section{Teager Energy Signal Denoising Based on Wavelet Packet}

The collected vibration signals from rolling bearings running in complex conditions usually contain strong noises. In order to extract the fault features with high SNR, a wavelet packet was used to reduce noise existing in the Teager energy signal in this study.

Traditional denoising methods, such as low-pass filter high-pass filter, can eliminate only low-frequency or highfrequency noise, but wavelet packet transforms, which have the function of multiresolution analysis, can analyze the signal both in the time domain and the frequency domain. Wavelet packet transforms can decompose signals into different bands and effectively distinguish the noise from the useful signal in different frequency bands, eliminating the noise of the signal in various frequency bands.

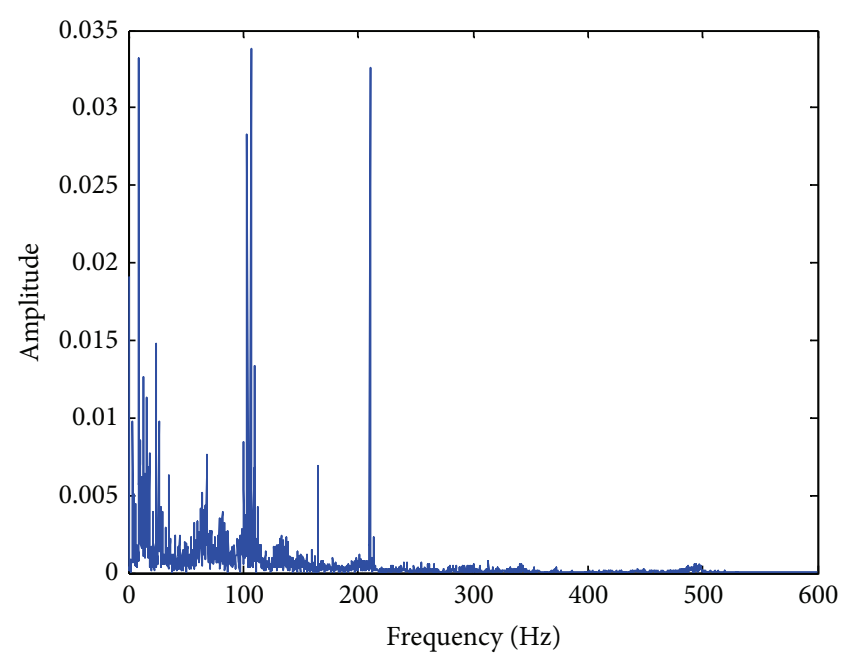

FIGURE 11: Frequency spectrum of the vibration signal at normal conditions.

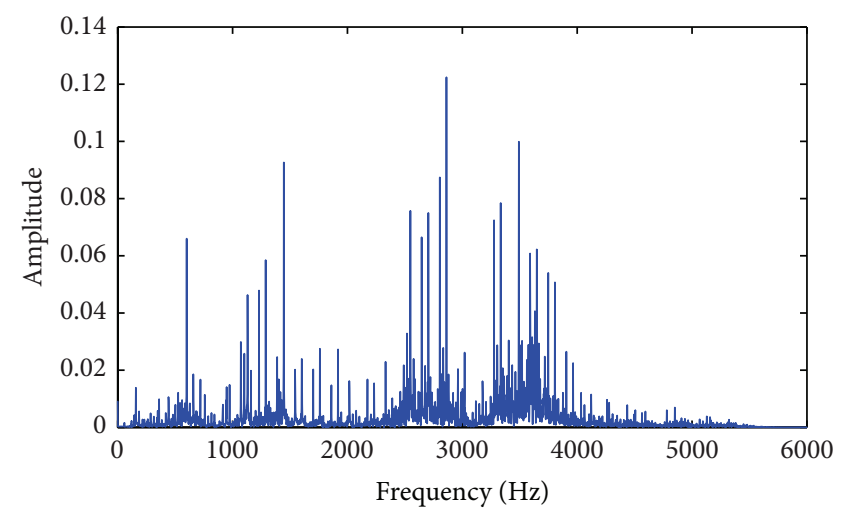

FIGURE 12: Frequency spectrum of the vibration signal at inner ring fault conditions.

The TEO can calculate the total energy of the sample points in original vibration signal. Because the original signal of a rolling bearing usually contains a strong background noise, the time domain waveform of Teager energy is still influenced by the energy of the noise. Wavelet packet-based denoising can effectively eliminate the random noise of the transient signal; therefore, it was used to reduce the noise in the Teager energy signal and extract the transient impact component.

As shown in Figure 6, the transient impact components can be highlighted with the effect of the noise reduced.

\section{Fault Pattern Classification Based on the Elman Neural Network}

For the extracted feature vectors by the TEO, neural networks are always used to classify the fault mode. In this study, the Elman neural network was used for fault classification.

The Elman neural network includes input, output, hidden, and context layers. When the output of the hidden layer neurons goes through the context layer, it associates with 
the input of the hidden layer [12]. This type of association is sensitive to the historical state of data; internal feedback increases the capacity of the network to deal with dynamic information, overcoming the drawback of the feed-forward network, which does not have dynamic characteristics. Therefore, compared with other neural networks, the Elman neural network is more applicable to classifying the fault mode. The structure of the Elman neural network is shown in Figure 7.

The transfer function of the hidden layer in the Elman neural network is a sigmoid function. The activation function of the output layer neuron is a linear function. The nonlinear state equations of the network are

$$
\begin{gathered}
y(k)=g\left[w^{3} x(k)\right], \\
x(k)=f\left[w^{1} x_{c}(k)+w^{2} u(k-1)\right], \\
x_{c}(k)=x(k-1),
\end{gathered}
$$

where $y$ represents the output vector of the network, $u$ is the input vector of the network, $x$ denotes the output vector of the hidden layer, $x_{c}$ represents the feedback state vector, $w^{3}$ is the connection matrix from the context layer to the output layer, $w^{2}$ is the connection matrix from the hidden layer to the context layer, $w^{1}$ represents the connection layer from the input layer to the hidden layer, $g(\cdot)$ denotes the activity function of the output neurons, and $f(\cdot)$ represents the transfer function of the hidden layer.

\section{Experimental Results Analysis}

A cyclical shock will be generated when a bearing works. The frequency of this cyclical shock reflects the cause of the bearing fault. The feature frequency caused by the inner ring failure is

$$
F_{\text {In }}=\frac{1}{2} f_{n}\left(1+\frac{d}{D} \cdot \cos \emptyset\right) Z_{b}
$$

The feature frequency caused by the outer ring failure is

$$
F_{\text {Out }}=\frac{1}{2} f_{n}\left(1-\frac{d}{D} \cdot \cos \emptyset\right) Z_{b}
$$

The feature frequency caused by the rolling element failure is expressed as follows:

$$
F_{\text {Ball }}=\frac{1}{2} f_{n}\left[1-\left(\frac{d}{D} \cdot \cos \emptyset\right)^{2}\right] \frac{D}{d},
$$

where $d$ represents the inner diameter, $D$ represents the outer diameter, $Z_{b}$ denotes the number of rolling elements, and $\emptyset$ is the contact angle.

All the rolling bearing data used in this study were acquired by the Bearing Data Center of Case Western Reserve University. The bearing used was a 6205-2RS JEM SKF deep groove ball bearing. The motor speeds of the training and test data were 1750 and $1772 \mathrm{rpm}$, respectively. The vibration data were collected using accelerometers. The digital data were

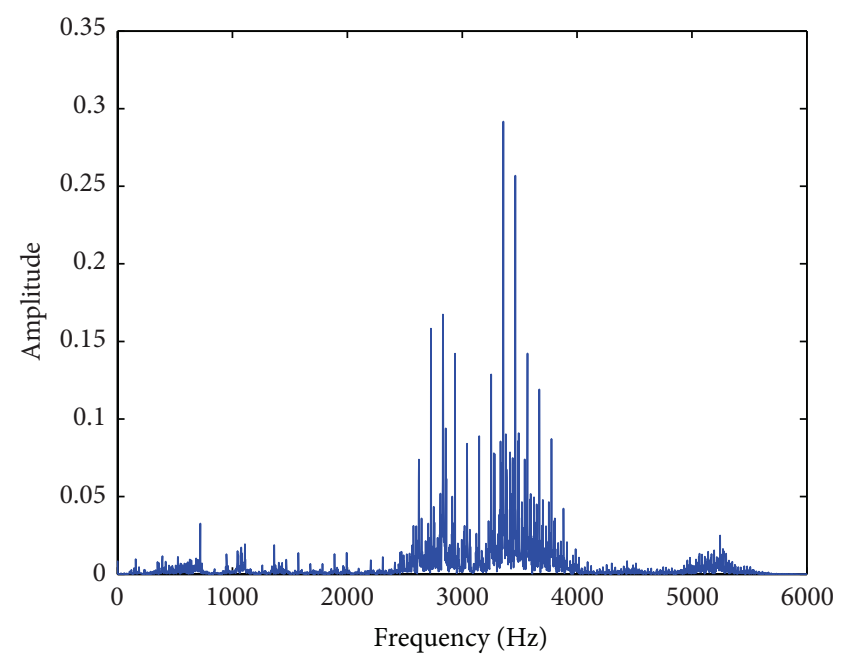

FIGURE 13: Frequency spectrum of the vibration signal at outer ring fault conditions.

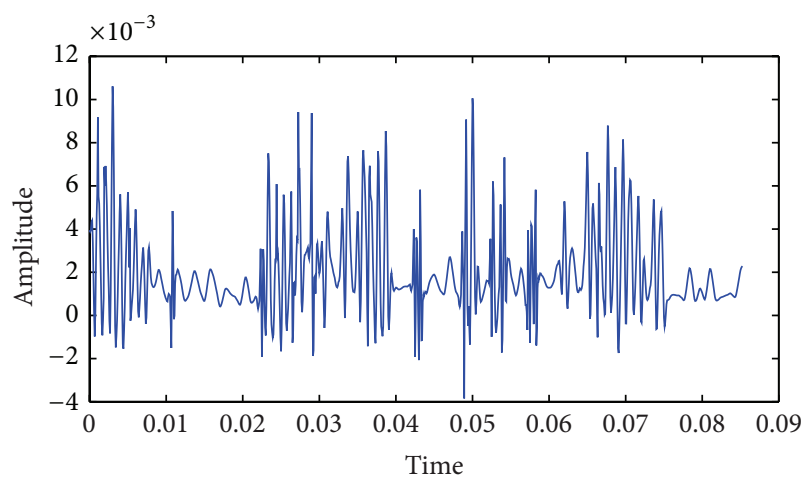

FIGURE 14: Time domain waveform of Teager energy in a normal bearing after wavelet packet-based denoising.

collected at a speed of 12000 samples per second. The detailed bearing information is shown in Table 2 .

On the basis of (11), (12), and (13), the feature frequency can be calculated as $F_{\text {In }}=157.94 \mathrm{~Hz}, F_{\text {Out }}=104.56 \mathrm{~Hz}$.

The figures discussed in the succeeding statements show the vibration signals in the time domain, the frequency spectrum, and the Teager spectrum of each failure mode. Figures 8, 9, and 10 illustrate the time domain waveforms of each fault. In the time domain waveforms, the cyclical shock features are not observable because the given signals are affected by noise. The fault modes cannot be distinguished from the time domain waveforms. Figures 11, 12, and 13 show the frequency spectrum of each fault. The feature frequencies of the fault are not easily distinguishable because of the resonance frequencies in the frequency spectrum. Figures 14, 15 , and 16 indicate the Teager energy time domain waveform of each fault after wavelet packet-based denoising. The TEO highlights the transient impact feature, so that such features caused by the fault become more visible. The time interval between two adjacent impacts corresponds to fault feature frequencies. 


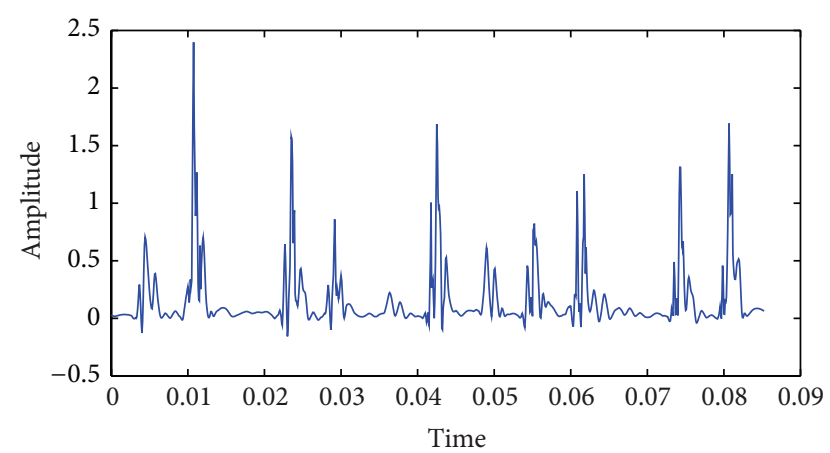

Figure 15: Time domain waveform of Teager energy at inner ring fault conditions after wavelet packet-based denoising.

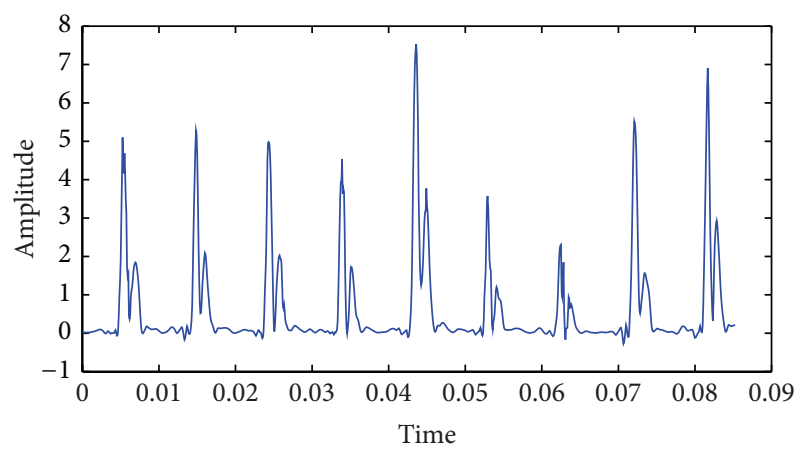

FIGURE 16: Time domain waveform of Teager energy at outer ring fault conditions after wavelet packet-based denosing.

Figures 17, 18, and 19 show the Teager spectrum of each fault. The fundamental and multiplier frequencies are clearly observable from the Teager spectrum.

The frequency spectrum of each fault mode shows that the resonance frequencies of the different fault modes vary confirming that the ratio of the energy of resonance frequency to total energy can be used as a feature vector.

The amplitudes of the Teager spectrum in the inner and outer ring fault frequencies, as well as the ratio of the energy of resonance frequency to total energy, were extracted as the feature vectors, as listed in Table 3. The weighted Teager spectrum in the fault frequency and around $\Delta f=2 \mathrm{~Hz}$ was extracted as a feature vector to avoid a frequency leak error.

To confirm the effectiveness of the proposed method under variable conditions, we used two types of bearing vibration signals with different motor speeds to detect the fault modes (inner ring fault, outer ring fault, or normal) in this study.

A total of 60 groups of training data (normal data, inner ring fault data, and outer ring fault data; each mode with 20 groups) were used. The motor speed was $1750 \mathrm{rpm}$. The feature vectors were used to train the Elman neural network. According to the dimensionality of the feature vectors, the number of input nodes was set as three. The inputs of the Elman neural network were the fault feature vectors. The target outputs were set as $(1,0,0),(0,1,0)$, and $(0,0,1)$, representing the normal bearing, inner ring fault, and outer

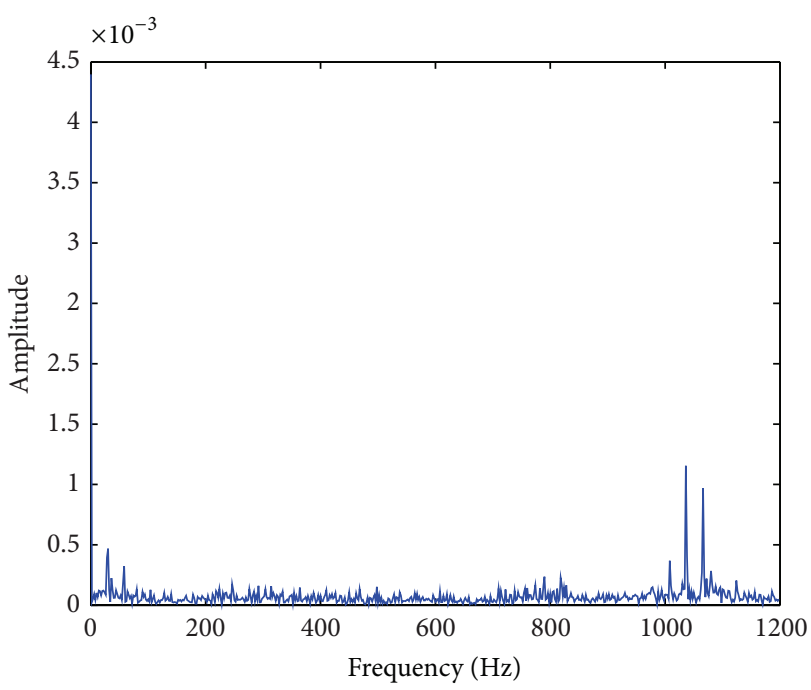

FIGURE 17: Teager spectrum of the normal bearing.

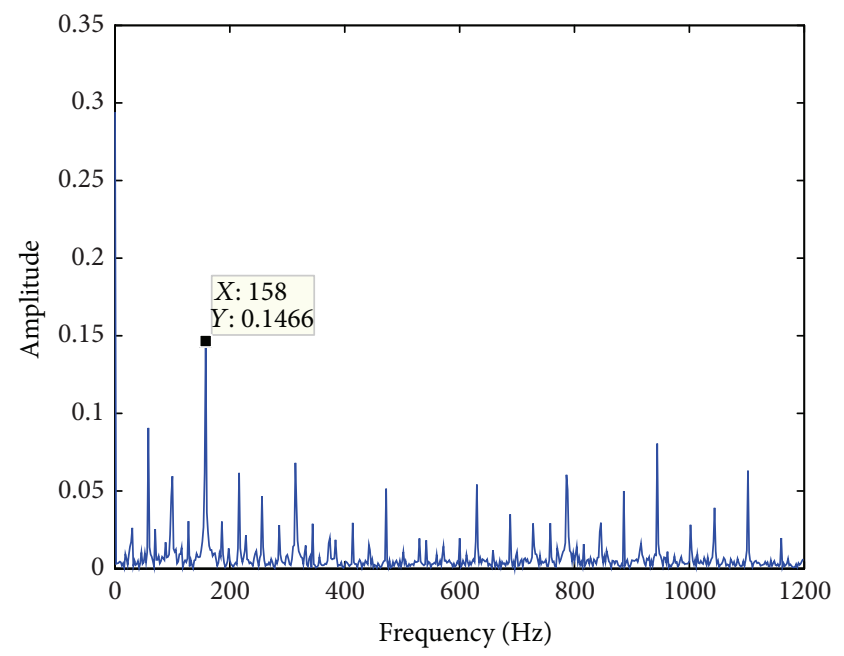

FIGURE 18: Teager spectrum of the inner ring fault bearing.

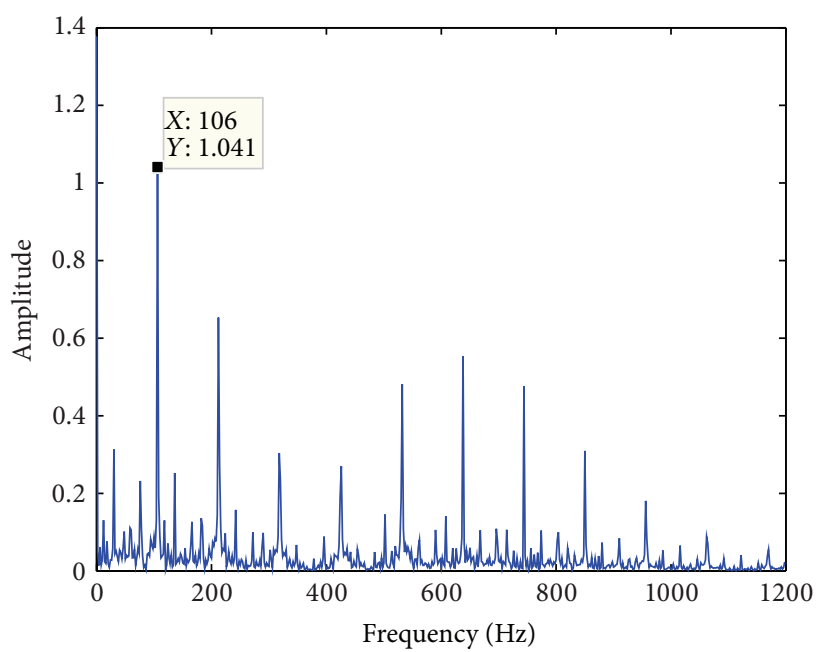

FIGURE 19: Teager spectrum of the outer ring fault bearing. 


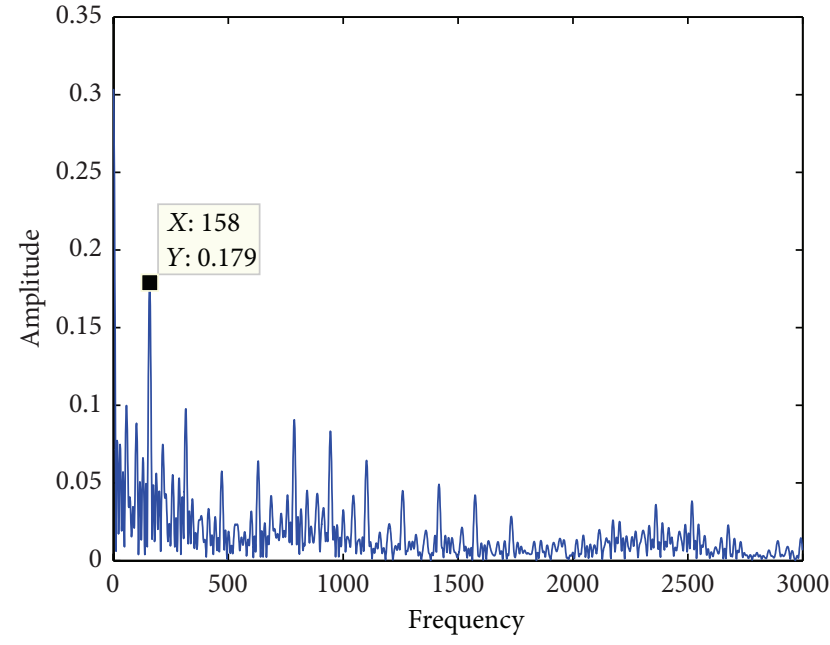

(a) $1750 \mathrm{r} / \mathrm{min}$

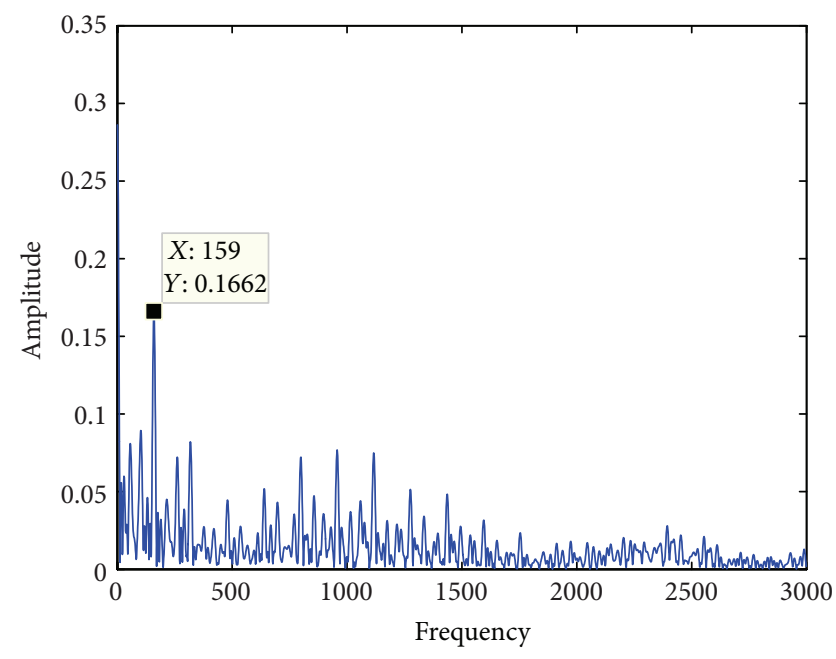

(b) $1772 \mathrm{r} / \mathrm{min}$

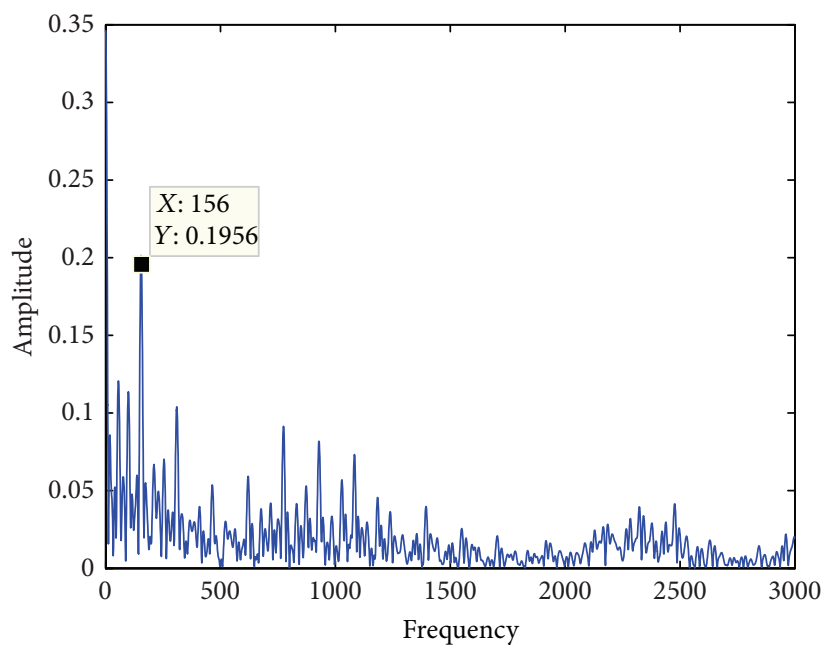

(c) $1721 \mathrm{r} / \mathrm{min}$

FIGURE 20: Teager spectrums of the inner ring fault bearing working in different conditions.

ring fault, respectively. The training data components are shown in Table 4.

To further validate the effectiveness of the proposed method under variable conditions, 15 groups of test data (normal data, inner ring fault data, and outer ring fault data; each mode with 5 groups) were collected under a different motor speed. These test data were collected at a motor speed of $1772 \mathrm{rpm}$. The experimental results are listed in Table 5.

To verify the robustness and applicability of the proposed method, three Teager spectrums of the inner ring fault bearing working in different conditions are shown in Figure 20.

When the speed of the bearing increases from $1721 \mathrm{r} / \mathrm{min}$ to $1772 \mathrm{r} / \mathrm{min}$, the fault frequency correspondingly changes from $156 \mathrm{~Hz}$ to $159 \mathrm{~Hz}$. In this study, the weighted Teager spectrum in the fault frequency and around $( \pm 2 \mathrm{~Hz})$ was an extracted feature vector. It cannot only avoid a frequency leak error but also cover the fault frequencies working in different conditions. Thus, the robustness of the proposed method is improved and suitable for different conditions.
The TEO can extract the transient impact feature of the faulty bearing, and the Elman neural network can classify the bearing failure mode. In addition, because the motor speed of the test data was different from that of the training data, the method exhibited good robustness, indicating applicability to different operating conditions.

\section{Conclusion}

The TEO can calculate the instantaneous total energy of signals; thus, it is suitable for detecting transient signals and highlights the impact characteristics of transient peak signals. With consideration for the impact characteristics of the vibration signal of a faulty bearing, this paper presents a TEO and Elman neural network-based method for detecting bearing faults. The TEO is advantageous for detecting the impact characteristics of a signal and can therefore effectively detect the impact signal of a faulty bearing. Moreover, the 
TEO exhibits a good time resolution and self-adaptability to transient signals, showing better robustness in bearing fault detection.

\section{Acknowledgments}

This research is supported by the National Natural Science Foundation of China (Grant nos. 61074083, 50705005, and 51105019) and by the Technology Foundation Program of National Defense (Grant no. Z132010B004).

\section{References}

[1] A. F. Khan, Condition Monitoring of Rolling Element Bearing, A Comparative Study of Vibration Based Techniques, University of Windsor, Ontario, Canada, 1990.

[2] Y. T. Su and Y. T. Sheen, "On the detectability of roller bearing damage by frequency analysis," Proceedings of the Institution of Mechanical Engineers C, vol. 207, no. 1, pp. 23-32, 1993.

[3] G. White, "Amplitude demodulation. A new tool for predictive maintenance," Sound and Vibration, vol. 25, no. 9, pp. 14-18, 1991.

[4] S. McMahon, "Condition monitoring of bearing using ESP," Condition Monitoring and Diagnostic Technology, vol. 2, no. 1, pp. 21-25, 1991.

[5] G. A. Ratcliffe, "Condition monitoring of rolling element bearings using the envelope technique," in Proceedings of the I.Mech.E. Seminar on Machine Condition Monitoring, pp. 55-65, 1990.

[6] J. Mathew, "Machine condition monitoring using vibration analysis," Journal of the Australian Acoustical Society, vol. 15, no. 1, pp. 7-13, 1987.

[7] X. Zhao, "The vibrating diagnosis method for rolling bearing fault," Journal of Chongqing University of Science and Technology, vol. 9, no. 1, pp. 41-44, 2007.

[8] J. F. Kaiser, "On a simple algorithm to calculate the "energy" of a signal," in Proceedings of IEEE International Conference on Acoustics, Speech, and Signal Processing (ICASSP '90), vol. 1, pp. 381-384, April 1990.

[9] L. Hongxing, C. Tao, Q. Liangsheng, L. Zhenuiu, and Y. Lizhu, "Energy operator demodulating approach and its application in mechanical signal demodulations," Chinese Journal of Mechanical Engineering, vol. 34, no. 5, pp. 85-90, 1998.

[10] A. M. Bassiuny and X. Li, "Flute breakage detection during end milling using Hilbert-Huang transform and smoothed nonlinear energy operator," International Journal of Machine Tools and Manufacture, vol. 47, no. 6, pp. 1011-1020, 2007.

[11] A. Potamianos and P. Maragos, "A comparison of the energy operator and the Hilbert transform approach to signal and speech demodulation," Signal Processing, vol. 37, no. 1, pp. 95120, 1994

[12] G. Yu, C. Li, and S. Kamarthi, "Machine fault diagnosis using a cluster-based wavelet feature extraction and probabilistic neural networks," International Journal of Advanced Manufacturing Technology, vol. 42, no. 1-2, pp. 145-151, 2009. 


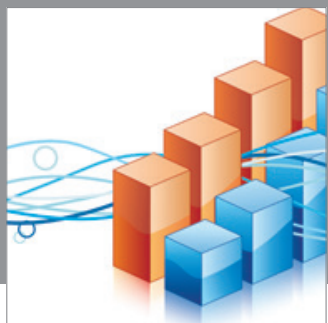

Advances in

Operations Research

mansans

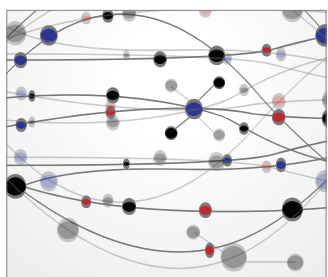

The Scientific World Journal
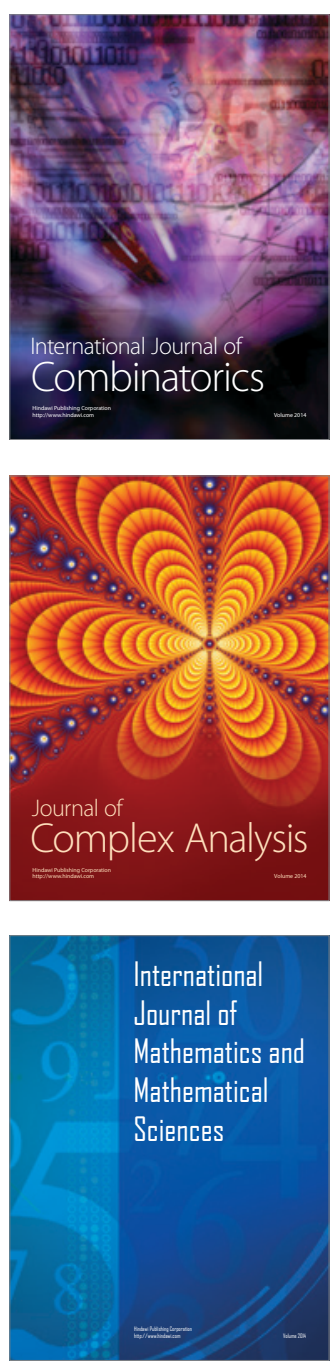
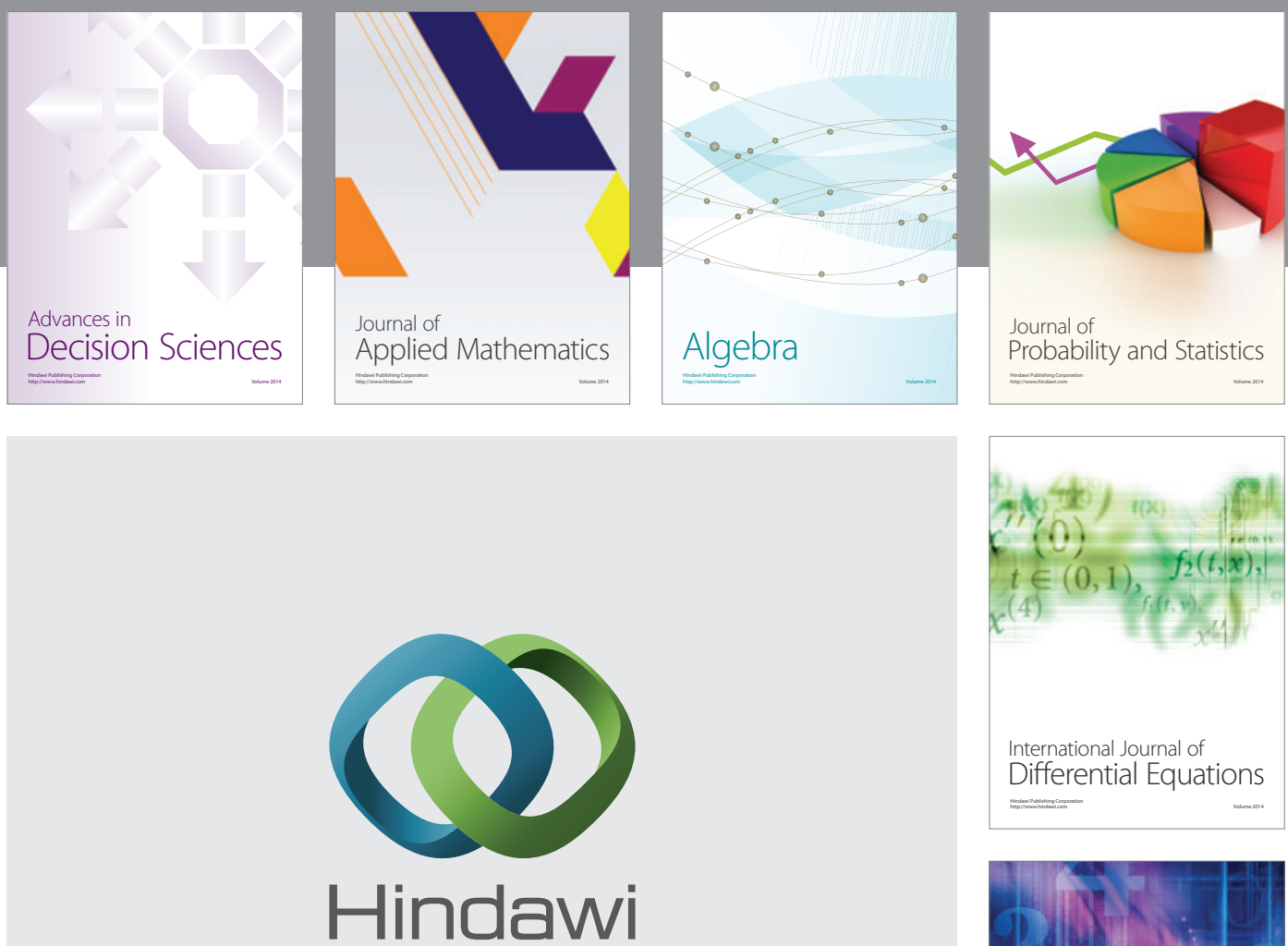

Submit your manuscripts at http://www.hindawi.com
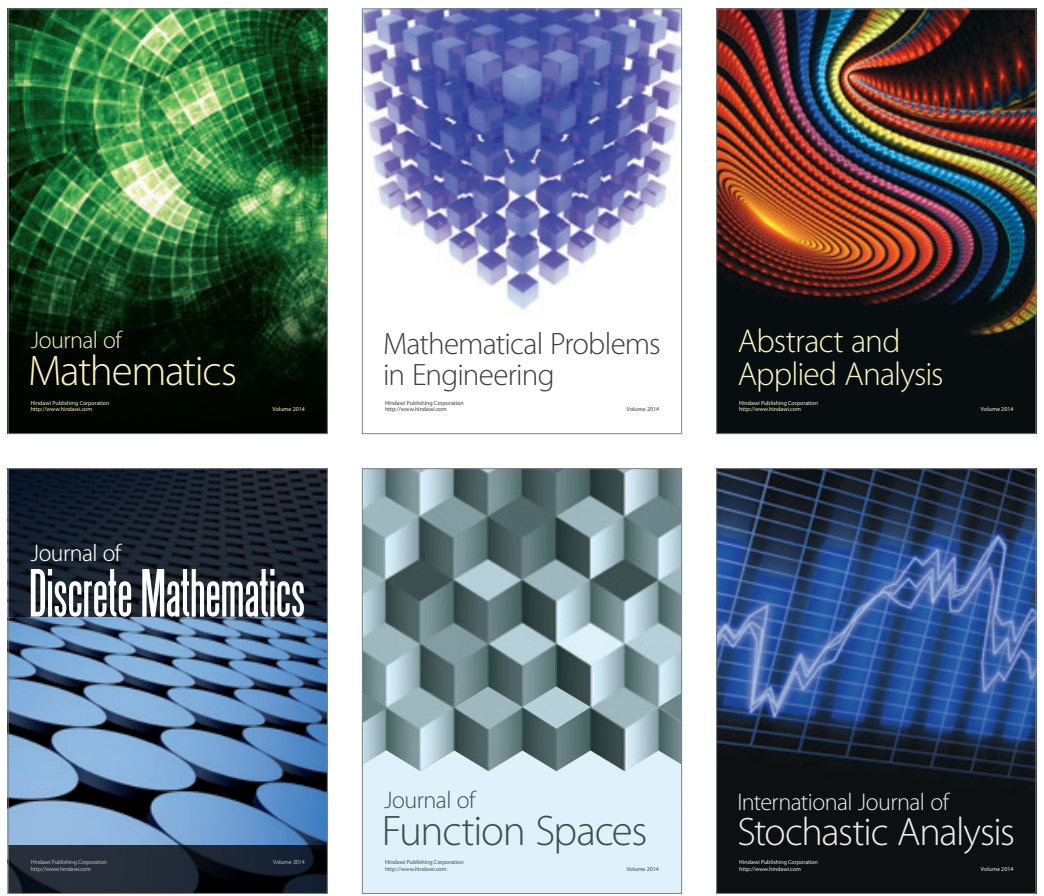

Journal of

Function Spaces

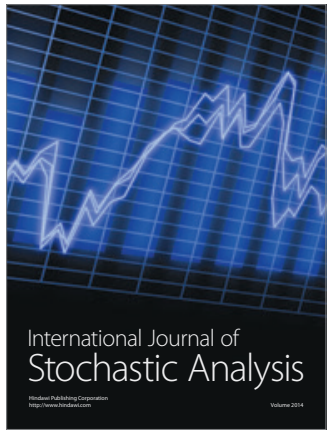

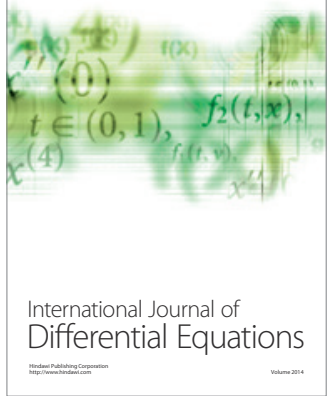
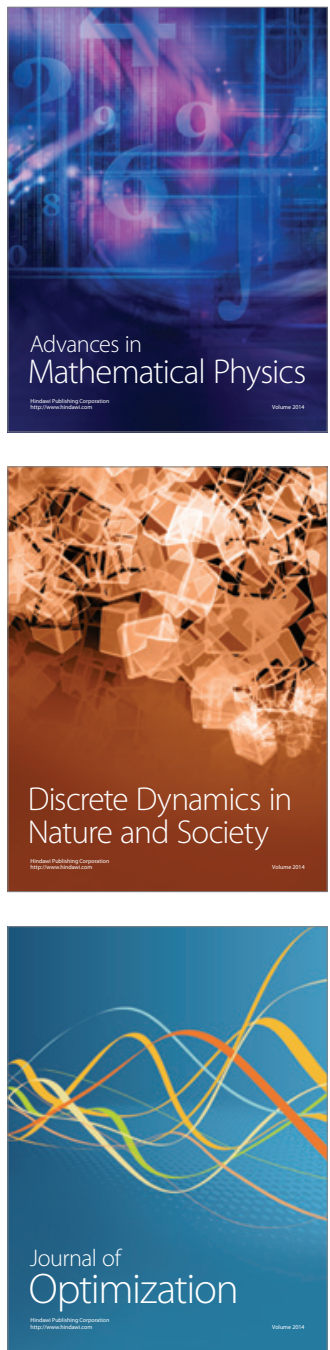